\title{
El Magisterio de Francisco sobre la mujer Continuidad, novedad y desafío
}

\author{
Miren JunKal Guevara \\ Facultad de Teología de Granada (España) \\ junkalguevara@yahoo.es \\ (D) https://orcid.org/0000-0003-1097-1858
}

Resumen: El pontificado de Francisco parece haber agitado los temas relacionados con el papel de la mujer en la Iglesia, no sólo porque desarrollamos una acción más reflexiva y reivindicativa sobre nuestro ser en comunidad católica, sino también porque las palabras y los gestos del Papa sacuden la cuestión en el seno de la Iglesia católica. Este magisterio de Francisco en acción, se entiende en el marco del magisterio sobre la mujer inspirado por el Concilio Vaticano II, que se examina en el trabajo, pero adquiere tintes de novedad y plantea desafíos importantes para la Iglesia del s. XXI. El artículo trata de descubrir las grandes líneas que recorren la agenda del Pontífice en los temas relacionados con la mujer, para tratar de comprender mejor su pensamiento, el trasfondo de algunas de sus decisiones de gobierno y su aportación a la comprensión de la mujer en el marco del pensamiento de los papas del s. XX.

Palabras clave: Francisco, teología de la mujer, genio femenino, jurisdicción y orden.

Abstract: The pontificate of Francis seems to have agitated issues related to the role of women in the Church. Women have begun to reflect on and reclaim their position in the Church and the Pope's words and gestures on the subject have shaken the foundations of the Catholic Church. The Magisterium of Pope Francis on women and their actions, inspired by the Second Vatican Council, are examined in this study. The actions of the Magisterium of Pope Francis have acquired new overtones that pose important challenges for the Church of the $21^{\text {st }}$ century. This article aims to uncover the main goals on the Pope's agenda on issues related to women to understand his thinking, the background of some of his government decisions and his contribution to the place of women in the modern Church based on the frame of thought of $20^{\text {th }}$ century Popes.

Keywords: Pope Francis, Theology of Women, female genius, order and jurisdiction. 


\section{INTRODUCCIÓN}

En 2013, cuatro meses después de ser elegido Papa, en el viaje de regreso desde Brasil, -donde se había celebrado la Jornada mundial de la juventud-, frente a una pregunta a propósito del diaconado femenino y la presencia de la mujer en los dicasterios romanos, Francisco afirmó: "Creo que nosotros no hemos hecho todavía una teología profunda de la mujer en la Iglesia"1. Unos días después, en una entrevista con el director de la Civiltá Cattolica, se le preguntó, precisamente, sobre el papel de la mujer en la Iglesia, a lo que respondió:

Es necesario ampliar los espacios para una presencia femenina más incisiva en la Iglesia [...] Las mujeres están formulando cuestiones profundas que debemos afrontar. La Iglesia no puede ser ella misma sin la mujer y el papel que ésta desempeña [...] En los lugares donde se toman las decisiones importantes es necesario el genio femenino ${ }^{2}$.

Estas afirmaciones, que se han ido repitiendo a lo largo de su pontificado, permiten reconocer que la mujer constituye un punto importante en su agenda, haciendo hincapié en dos grandes líneas: por un lado, lo que él llama "teología de la mujer en la Iglesia” y, por otro, la ampliación de espacios para una presencia femenina más incisiva, particularmente necesaria en los lugares donde se toman las decisiones importantes.

La explicación detallada de la expresión "teología de la mujer" y su evolución a lo largo del tiempo, no resulta posible en este momento ${ }^{3}$. Con todo, es necesario decir que la fórmula comenzó a prodigarse durante el pontificado de Pío XII, al hilo de la cada vez mayor presencia de la mujer en la vida pública. Ese Papa, a diferencia de sus predecesores, abordó el trabajo femenino fuera del hogar como una oportunidad de los católicos para mostrar públicamente un modelo concreto de familia, y, en ese marco, alentó la reflexión de los teólogos en torno al rol propio y singular de las mujeres en la familia y la vida social (Pío XII, discurso La mujer en la actualidad, 21 de octubre de 1945).

\footnotetext{
${ }^{1}$ FranCISCO, "Viaje Apostólico a Río de Janeiro con ocasión de la XXVIII Jornada Mundial de la juventud; Conferencia de prensa del Santo Padre Francisco durante el vuelo de regreso a Roma", 28 de julio de 2013, en línea: http://www.vatican.va/content/francesco/es/speeches/2013/july/documents/papafrancesco_20130728_gmg-conferenza-stampa.html, (consulta 3/12/2019).

2 A. SPADARO, "Entrevista al Papa", en línea: http://www.vatican.va/content/francesco/es/speeches/2013/september/documents/pap a-francesco_20130921_intervista-spadaro.html (consulta 1/12/2019).

${ }^{3}$ Nosotras mismas hemos profundizado en la cuestión "teología de la mujer", Véase M. J. GuevarA, "Mujer y Teología”, Sal terrae: Revista de teología pastoral 107 (2019) 65-84. Además, puede ayudar la consulta de M ZUBÍA, Para nuestra memoria histórica: las mujeres en la voz de los Papas (Aletheia 7; Verbo Divino, Estella 2011).
} 
Con este impulso fueron surgiendo en los años 50' del siglo pasado teologías de la feminidad o femineidad, elaboradas, principalmente, por hombres ${ }^{4}$, que trataban de valorar desde la perspectiva teológica los roles atribuidos tradicionalmente a ellas. Estas teologías, que otorgaban la misma dignidad y vocación profunda al hombre y a la mujer, a veces en una clave muy esencialista, muy modulada por la naturaleza, pasaban por alto el discernimiento de la incidencia que, en la configuración de los roles que desempeñamos hombres y mujeres, tienen aspectos como la cultura, la historia y la educación.

De manera que, en este artículo concentraremos nuestro estudio en las dos grandes líneas de trabajo marcadas en la agenda del Papa Francisco: las claves de una "teología de la mujer", y los signos de una presencia femenina más incisiva allí donde en la Iglesia se toman decisiones importantes.

Nos interesa comprender más en profundidad su pensamiento, sus límites y sus logros; el trasfondo de algunas de sus decisiones de gobierno, y, en definitiva, su aportación a esta teología en el marco del pensamiento de los pontífices del s. XX.

\section{LAS LÍNEAS FUNDAMENTALES DEL PENSAMIENTO DEL PAPA}

El éxito del Papa Francisco como comunicador, sobre el que se han escrito numerosos estudios, nos obliga a prestar atención a los documentos magisteriales de mayor rango, a todo lo que se ha llamado "magisterio en acción", el de un "pastor que teologiza"6. Pero, además, a los gestos y las palabras durante sus viajes apostólicos y audiencias; los diálogos espontáneos, las entrevistas en los medios de comunicación. La revista Time ha sabido resumir bien esa capacidad de comunicar su pensamiento cuando dice que

\footnotetext{
4 Pero puede encontrarse también en estudios de mujeres, cfr. C. ÁLVAREZ, "Hacia una teología de lo femenino. En torno a la carta Mulieris dignitatem" en J. J PÉREZ SOBA - A GARCÍA DE LA CUERDA - Á CASTAÑo (eds.), En la escuela del Logos. A Pablo Dominguez in memoriam II (Collectanea Matritensia 6; Publicaciones de la Facultad de Teología San Dámaso, Madrid 2010) 241-261.

5 JesuitAs-CPAL, “El Papa Francisco y su pensamiento: Magisterio en acción”, en línea: https://jesuitas.lat/es/noticias/406-el-papa-francisco-y-su-pensamiento-magisterio-enaccion, (consulta 15/05/2020).

'J. C. SCANnONE, "El Papa Francisco no es un teólogo, es un pastor que teologiza", en línea: https://www.comillas.edu/es/noticias-comillas/4237-el-papa-francisco-no-es-un-teologoes-un-pastor-que-teologiza, (consulta 4/12/2019).
} 
Francisco ha conseguido conectar con el público en general y con los medios porque le duele lo que a la gente le duele, y habla de lo que habla la gente ${ }^{7}$.

Esa conexión se traduce en una simplicidad en lo exterior (insignias, vestiduras, vivienda, transporte) que lo hace muy creíble y muy cercano; una significatividad fuerte de sus gestos (lavar los pies a mujeres, abrir la misa diaria al público, bendecir a los ateos); y una notable espontaneidad y proximidad en las distancias cortas (improvisa diálogos con los asistentes, es directo). Pues, como bien menciona, promueve "una Iglesia que sabe ponerse en salida, mezclándose con las inquietudes, los dolores y las esperanzas de este mundo globalizado" .

\subsection{Mirada general}

Así, nuestro estudio del pensamiento del Papa sobre las mujeres tratará de seguirle la pista a uno y otro magisterio. Examinaremos las dos encíclicas que ha publicado, Lumen fidei (2013) y Laudato si' (2015)'; las cinco exhortaciones apostólicas Evangelii gaudium (2013), Amoris laetitia (2016), Gaudete et exultate (2018), Christus vivit (2019) y Querida Amazonia (2020), así como sus discursos, viajes apostólicos, entrevistas... Intentaremos, pues, rastrear las claves fundamentales de su pensamiento, esas que dan forma al núcleo de la agenda de su ministerio en la Iglesia universal.

Antes de comenzar, es importante notar que cualquier consideración de la percepción que Francisco tiene de la humanidad que hoy transita por los caminos de la historia, por muy general que sea, tiene que reconocer que este Papa ve hombres y mujeres que viven precariamente (EG 52), y para los que la alegría de creer constituye algo de vital importancia (EG 86); son también "mujeres y hombres del mundo posmoderno que corren el riesgo de volverse individualistas" (LS 162). Esa humanidad reclama de los bautizados "una auténtica fe -que nunca es cómoda e individualista- y que siempre implica un profundo deseo de cambiar el mundo, de transmitir valores, de dejar algo mejor detrás de nuestro paso por la tierra" (EG 183).

El Pontífice confiesa "amamos este magnífico planeta donde Dios nos ha puesto, y amamos a la humanidad que lo habita, con todos sus dramas y

${ }^{7}$ C. JimÉneZ, "La comunicación de Francisco. Los secretos de un éxito mediático", Sal Terrae 103 (2015) 196.

${ }^{8}$ M. GALlO, "Papa Francisco, un constructor de puentes", Vida Nueva - Revistay portal de noticias religiosas y de Iglesia, 18 de junio de 2019, en línea:

https://www.vidanuevadigital.com/tribuna/papa-francisco-un-constructor-de-puentes/ (consulta 3/12/2019).

9 Al momento de la elaboración de este trabajo, el Papa no había publicado aún la encíclica Fratelli tutti. 
cansancios, con sus anhelos y esperanzas, con sus valores y fragilidades. La tierra es nuestra casa común y todos somos hermanos" (EG 183).

En medio de esa humanidad, se fija en el semblante de las mujeres que conoce bien; en los rostros de la exclusión que sufren los pobres de América Latina y, particularmente, en las mujeres, que son para él "luchadoras, esperanzadas a pesar de las circunstancias, madres que en infinidad de ocasiones sacan adelante solas a sus hijos y que, como María, han visto muchas veces cómo les arrebatan criminalmente a sus hijos" ${ }^{\prime 10}$. Esa es también la actitud que elogia en las mujeres de la vida consagrada que tienen la "maternidad de la Iglesia que las hace estar cerca, en primera línea" ${ }^{\text {" }}$.

Por eso recuerda constantemente a las más vulnerables, "que sufren situaciones de exclusión, maltrato y violencia" (EG 212); mujeres que se encuentran en situaciones muy brutales, donde el aborto se les presenta como una rápida solución a sus profundas angustias (EG 214); madres adolescentes, mujeres solas en medio de los movimientos migratorios y víctimas de la trata de personas (AL 197).

Es en este marco en el que hay que interpretar las afirmaciones sobre las mujeres en los grandes documentos magisteriales del Papa Francisco que, mostrando una clara sintonía con los logros y avances de sus predecesores en materia de pensamiento sobre la mujer, subrayan acentos muy propios que jalonan los perfiles de lo que puede ser su peculiar aportación.

Ya desde la publicación de Evangelii gaudium -que contiene la hoja de ruta de su pontificado-, percibimos la sintonía de Francisco con la teología del Concilio Vaticano II que sancionó el reconocimiento de hombre y mujer como imago Dei, y lo convirtió en el núcleo de cualquier antropología teológica.

Así, el Papa confirma la igual dignidad de hombre y mujer, apuntando que las reivindicaciones de los legítimos derechos que se derivan de ello, "plantean a la Iglesia profundas preguntas que la desafían y que no se pueden eludir superficialmente" (EG 104). Y advierte en uno de sus últimos textos que "una Iglesia demasiado temerosa y estructurada puede ser permanentemente crítica ante todos los discursos sobre la defensa de los derechos de las mujeres, y señalar constantemente los riesgos y los posibles errores de esos reclamos" (CHV 42).

De la misma manera que Juan XXIII consideró un signo de los tiempos la presencia femenina en la vida pública (Pacem in terris 41), el reconocimiento cada

\footnotetext{
10 M. T. COMPTE, Diez cosas que el Papa Francisco propone a las mujeres (Publicaciones Claretianas, Madrid 2018) 31.

${ }^{11}$ FrANCISCO, "Discurso a los jóvenes consagrados", 17 de septiembre de 2015, en línea: http://www.vatican.va/content/francesco/it/speeches/2015/september/documents/papa -francesco_20150917_giovani-consacrati.html, (consulta 3/12/2019).
} 
vez más claro de su dignidad y derechos está visto por el Papa como una obra del Espíritu (AL 54), y, "precisamente, aun en épocas en que las mujeres fueron más relegadas, el Espíritu Santo suscitó santas cuya fascinación provocó nuevos dinamismos espirituales e importantes reformas en la Iglesia" (GE 12). Los frutos de esta acción son para Francisco, entre otros, la superación de viejas formas de discriminación y el ejercicio de reciprocidad en el seno de las relaciones familiares (AL 54). Esta reciprocidad, como núcleo de las relaciones entre hombres y mujeres, surge de la mirada de una Iglesia viva que presta atención a las reivindicaciones de mayor justicia e igualdad (CHV 42) y está en la agenda de las cuestiones con las que los jóvenes desean confrontarse $(\mathrm{CHV}$ 81).

Así, no sorprende que el Papa haya utilizado la palabra en los viajes pastorales para hablar de las mujeres y denunciar el feminicidio y la violencia contra ellas (Perú); la esclavitud femenina e infantil (Tailandia); la tragedia humana de los migrantes y, particularmente, de las mujeres solas (Ciudad Juárez, México).

Además, en las audiencias a autoridades, colectivos e instituciones, ha aprovechado para denunciar, entre otras muchas cuestiones, que algunas mujeres son despedidas sólo por el hecho de estar embarazadas (miembros de la Unión cristiana de dirigentes empresariales, octubre 2015); que sus trabajos son precarios (dirigentes y trabajadores del Instituto nacional de seguridad social en Italia, noviembre 2015); que, frecuentemente, tienen peores trabajos, ganan menos y, a veces, incluso son explotadas (Confederación italiana de sindicatos de trabajadores, junio 2017); que son víctimas preferentes del tráfico de personas (día mundial contra la Trata de personas, julio 2019) y de la violencia doméstica (50 Jornada mundial de la paz, enero 2017).

Esa presencia social de las mujeres tan notable y, a la vez, tan difícil y sufriente, en muchos casos le lleva a reflexionar sobre las capacidades particulares o específicamente femeninas: "Una sensibilidad, una intuición y unas capacidades peculiares que suelen ser más propias de las mujeres que de los varones" (EG 103; AL 173). Y coloca como ejemplo la dedicación a los otros, que se expresa fundamentalmente -aunque no solo-, en la maternidad (EG 103). Estas capacidades son para Francisco el "genio femenino" (EG 103) del que habló Juan Pablo II, indispensable para la sociedad (AL 173), y que entraña una serie de responsabilidades.

Por otra parte, el Papa insiste constantemente en la necesidad de ahondar en el trabajo femenino, que no debe reducirse al debate en torno a las funciones que en ella puede desempeñar, y que todavía es una asignatura pendiente: "Lo importante es algo que va más allá de las funciones, que aún no ha madurado, 
que aún no hemos entendido correctamente""12. "nos quedamos solamente en la parte funcional, que es importante, que tienen que estar en los consejos, todo lo que se dijo, eso sí. Pero el papel de la mujer en la Iglesia va mucho más allá de la funcionalidad, y eso es lo que hay que seguir trabajando""13.

Este apunte del Papa, en la cuestión de la funcionalidad, me parece interesante para hacer notar que la participación más incisiva de las mujeres no puede plantearse en clave de reparto de poder porque, al final, se presenta repitiendo dinámicas de rivalidad y competitividad que, en nuestra opinión, debe ser analizada y corregida ${ }^{14}$. Quizás resulte más interesante pensar en la participación en clave de comunión sin dominación.

El Papa, como sus más inmediatos predecesores, reconoce "cómo muchas mujeres comparten responsabilidades pastorales junto con los sacerdotes, contribuyen al acompañamiento de personas, de familias o de grupos y brindan nuevos aportes a la reflexión teológica" (EG 103). Incluso, hace notar que las más jóvenes denuncian ya hoy una falta de liderazgo femenino en la Iglesia, y quieren aportar sus dones profesionales e intelectuales ( $\mathrm{CHV}$ 245). Probablemente por eso, una y otra vez, advierte de la necesidad de ampliar los espacios para una presencia femenina más incisiva en la Iglesia (EG 103).

En este sentido, como Pablo VI y Juan Pablo II, Francisco ha tenido que enfrentar la cuestión del sacerdocio ministerial de las mujeres y, aunque ha seguido el magisterio de Juan Pablo II (EG 104), porque "fue claro al respecto, y cerró la puerta y yo no voy a volver atrás en esto y fue un asunto tratado con seriedad y no un capricho"15, sí ha impulsado la reflexión en torno al diaconado femenino ${ }^{16} \mathrm{y}$, sobre todo, ha retomado la línea de argumentación indicada por

${ }^{12}$ FrANCISCO, "Diálogo improvisado del Papa con las Superioras Generales sobre los abusos y el diaconado femenino", audiencia a las participantes en el encuentro de la Unión Internacional de Superioras Generales (UISG), con motivo de la XXI Asamblea Plenaria, 10 de mayo de 2019, en línea:

https://press.vatican.va/content/salastampa/es/bollettino/pubblico/2019/05/10/uni.htm 1, (consulta 25/05/2020).

${ }^{13}$ FrANCISCO, "Sínodo Amazónico: Discurso final completo", 26 de octubre de 2019, en línea: https:/ / es.zenit.org/2019/10/26/discurso-del-papa-no-tenerle-miedo-a-las-organizacionesque-custodian-una-vida-especial/, (consulta 25/05/2020).

14 S. MARTíNEZ "Mujeres creyentes, culturas e Iglesias. Reformas para comunidades católicas vivas y en acción", Journal of the European Society of Women in Theological Research, 25 (2017) 143165.

15 P. PulleLlA, “Agencia Reuters entrevista al Papa sobre la actualidad internacional”, V atican News, 20 de junio de 2018, en línea: https://www.vaticannews.va/es/papa/news/201806/entrevista-papa-reuteurs-china-trump-migracion-cambio-climatico.html, (consulta $27 / 05 / 2020)$.

${ }^{16}$ FRANCISCO, "Diálogo improvisado del Papa con las Superioras Generales sobre los abusos y el diaconado femenino", audiencia a las participantes en el encuentro de la Unión 
Benedicto XVI para fundamentar la mayor participación de las mujeres en las instancias de decisión de la Iglesia (EG 104), instando a pastores y teólogos a reflexionar acerca del binomio potestad de orden-jurisdicción (EG 104).

Además, Francisco considera que la mujer tiene una función específica en el cristianismo que, al igual que Juan Pablo II, remite a la figura de la Virgen María: acoge, mantiene, se da sin medida y, así, hace visibles unas actitudes que son esenciales para la vida de la Iglesia. Esas capacidades del "genio femenino" se convierten en los principios inspiradores de la reforma de la Iglesia -incluida la de la curia romana-, pues la reforma que él considera prioritaria es la que afecta a las actitudes. María es "madre de la Iglesia evangelizadora [y que] sin ella no comprendemos el espíritu de la nueva evangelización" (EG 285), porque "lo que se entiende en general de la Iglesia, virgen y madre, se entiende en particular de la Virgen María" (EG 285). "Sin este estilo hablaríamos del pueblo de Dios, pero como una organización, quizás sindical, pero no como una familia nacida de la Madre Iglesia" ${ }^{17}$.

La fuerza de la imagen de la mujer madre le permite trasladarla, como sus predecesores, a la consideración de la Iglesia que para Francisco es "mujer y madre", porque "cuando olvidamos esto, es una Iglesia masculina sin esta dimensión, y tristemente se convierte en una Iglesia de solterones, que viven en este aislamiento, incapaces de amor, incapaces de fecundidad"18.

La institución, como cualquier madre, no puede permitirse ser autorreferencial, encorvada sobre sí misma y sus asuntos, con un débil pulso misionero" ${ }^{19}$. Eso no es sino "narcisismo que nos conduce a la mundanidad espiritual y al clericalismo sofisticado, y luego nos impide experimentar la dulce y confortadora alegría de evangelizar"20. La Iglesia se preocupa por todos sus

Internacional de Superioras Generales (UISG), con motivo de la XXI Asamblea Plenaria, 10 de mayo de 2019, en línea:

https://press.vatican.va/content/salastampa/es/bollettino/pubblico/2019/05/10/uni.htm 1, (consulta 25/05/2020).

${ }^{17}$ FRANCISCO, Encuentro "la protección de los menores en la Iglesia", 22 de febrero de 2019, en línea:

http://w2.vatican.va/content/francesco/es/speeches/2019/february/documents/papafrancesco_20190222_incontro-protezioneminori.html, (consulta 27/05/2020).

${ }^{18}$ FrAnCISCO, "La Iglesia es mujer y madre. Homilía en la Misa matutina de la capilla de la Domus Sanctaa Marthae”, 21 de mayo de 2018, en línea:

http://www.vatican.va/content/francesco/es/cotidie/2018/documents/papa-francescocotidie_20180521_iglesia-mujer-madre.html, consulta (27/05/2020).

${ }^{19}$ FranCISCO, "Viaje apostólico a Colombia: Encuentro con el Comité directivo del CELAM", 7 de septiembre de 2017, en línea:

http://www.vatican.va/content/francesco/es/speeches/2017/september/documents/pap a-francesco_20170907_viaggioapostolico-colombia-celam.html, (consulta 25/05/2020).

${ }^{20}$ FrANCISCO, "Carta a los participantes en la 105 Asamblea plenaria de la Conferencia Episcopal Argentina", 25 de marzo de 2013, en línea: 
hijos; es una Iglesia pobre para los pobres, porque a ellos les otorga Dios su primera misericordia (EG 198); una madre que se vuelca en aquellos bautizados que ya no tienen una pertenencia cordial y ya no experimentan el consuelo de la fe (EG 14). Así, la ternura de cualquier madre debe ser, entre otros, uno de los grandes motores de la Iglesia, porque "cuando los cristianos se olvidan de la esperanza y de la ternura, se convierten en una Iglesia fría, que no sabe dónde ir y se atasca en las ideologías, en las actitudes mundanas" 21 . En definitiva, "una Iglesia esposa, madre, servidora, facilitadora de la fe y no tanto controladora de la fe" ${ }^{\prime 2}$.

Por todo lo anterior, es fácil comprender que el Papa incida una y otra vez en la afirmación que aparece también en Juan Pablo II de que "hay un estilo mariano en la actividad evangelizadora de la Iglesia" (EG 288), y es ese estilo el que hace "que la Iglesia sea pueblo de Dios y no organización sindical"23 y muestre gestos de ternura y cariño, que "no son virtudes de los débiles, sino de los fuertes que no necesitan maltratar a otros para sentirse importantes" (EG 288).

Las claves del modelo de mujer que, a la luz de la revelación, Francisco propone en su magisterio, se perciben claramente porque se concentran, en principio, en la identificación de la mujer con la madre. Ellas, por madres, son quienes mejor visibilizan lo que significa darse sin reservas; saben testimoniar siempre, incluso en los peores momentos, la ternura, la entrega, la fuerza moral (AL 174), y, por eso, "el debilitamiento de la presencia materna con sus cualidades femeninas es un riesgo grave para nuestra tierra" (AL 173). Las madres, además, "transmiten a menudo también el sentido más profundo de la práctica religiosa” (AL 174) y "amparan al niño con su ternura y su compasión, le ayudan a despertar la confianza, a experimentar que el mundo es un lugar bueno que lo recibe, y esto permite desarrollar una autoestima que favorece la capacidad de intimidad y la empatía" (AL 175).

http://www.vatican.va/content/francesco/es/letters/2013/documents/papafrancesco_20130325_lettera-vescovi-argentina.html, (consulta 28/05/2020).

21 A. Tornielli, "Nunca hay que tener miedo de la ternura", PáginasDigital.es, 12 de diciembre de 2019, en línea:

http://www.paginasdigital.es/v_portal/informacion/informacionver.asp? $\operatorname{cod}=5092 \&$ te $=2$ 1\&idage $=9240,($ consulta 28/05/2020).

${ }^{22}$ FrANCISCO, "Viaje apostólico a Colombia: Encuentro con el Comité directivo del CELAM", 7 de septiembre de 2017, en línea:

http://www.vatican.va/content/francesco/es/speeches/2017/september/documents/pap a-francesco_20170907_viaggioapostolico-colombia-celam.html, (consulta 25/05/2020).

${ }^{23}$ FrANCISCO, "Encuentro "la protección de los menores en la Iglesia", 22 de febrero de 2019, en línea:

http://w2.vatican.va/content/francesco/es/speeches/2019/february/documents/papafrancesco_20190222_incontro-protezioneminori.html, (consulta 27/05/2020). 
Esta valoración de la mujer como madre permite comprender el rechazo y la denuncia explícita y recurrente al machismo, como una de las muchas debilidades de las culturas populares de pueblos católicos (EG 69), que se ha traducido en una larga historia de "sometimiento, de diversas formas de esclavitud, de abuso y de violencia" (CHV 42), y que ha urdido falsos argumentos contra la emancipación de la mujer (AL 54). Además, ha demostrado los excesos de las culturas patriarcales, donde la mujer era considerada de segunda clase (AL 54), subordinada al varón (AL 154).

Por último, siguiendo el pensamiento de sus más inmediatos predecesores, Francisco se pronuncia sobre el feminismo que valora "cuando no pretende la uniformidad ni la negación de la maternidad" (AL 173), y que puede ser un signo del espíritu que permita ahondar en la dignidad de la mujer y sus derechos (AL 54). Y que, además, se define en relación a la ideología de género o "utopía de lo neutro" 24 , que "niega la diferencia y la reciprocidad natural de hombre y de mujer; presenta una sociedad sin diferencias de sexo, y vacía el fundamento antropológico de la familia" (AL 56). También "en vez de combatir las interpretaciones negativas de la diferencia sexual, que mortifican su valencia irreductible para la dignidad humana, se quiere cancelar, de hecho, esta diferencia, proponiendo técnicas y prácticas que hacen que sea irrelevante para el desarrollo de la persona y de las relaciones humanas" ${ }^{\text {25 }}$.

\subsection{Los gestos más sobresalientes de su acción de gobierno}

Antes de examinar las opciones de gobierno, que han tratado de favorecer una presencia más incisiva de las mujeres en espacios de toma de decisiones en la Iglesia, es importante tener en cuenta que, desde el principio de su pontificado, el Papa se ha mostrado convencido de la necesidad que tiene la Iglesia -en este momento de la historia-, de una reforma de las estructuras que coloque a los agentes pastorales en constante actitud de salida y favorezca así la respuesta (EG 27).

Además, como él mismo ha hecho notar, la sinodalidad, que es uno de los grandes logros eclesiológicos del Concilio Vaticano II, se ha convertido en una de las reclamaciones del momento histórico en el que vivimos y "exige de la Iglesia el fortalecimiento de las sinergias en todos los ámbitos de su misión.

${ }^{24}$ FrANCISCO, "A los participantes en la Asamblea general de los miembros de la Pontificia Academia para la Vida", 5 de octubre de 2017, en línea:

http://w2.vatican.va/content/francesco/es/speeches/2017/october/documents/papafrancesco_20171005_assemblea-pav.html, (consulta 27/05/2020).

25 FrANCISCO, “A los participantes en la Asamblea general de los miembros de la Pontificia Academia para la Vida. 
Precisamente el camino de la sinodalidad es el camino que Dios espera de la Iglesia del tercer milenio"26.

Por otra parte, el CIC de 1983 ya prevé que las mujeres puedan participar de alguna manera en órganos ejecutivos desde donde se gobierna la Iglesia universal: ser consultoras en todos los dicasterios de la curia romana; delegadas y observadoras de la Santa Sede en organismos internacionales, conferencias (CIC 362.2) e incluso legados del Romano Pontífice (CIC 363.1) ${ }^{27}$.

Teniendo todo esto en cuenta, podemos entender el deseo del Papa de llevar más allá todavía la presencia de las mujeres en ambientes en los que se reflexiona y se discute sobre la labor de la Iglesia, espacios con cierta capacidad de incidir y crear una nueva cultura sobre la misión de las mujeres; lugares que reviertan la situación por la que la actividad de muchas en la Iglesia se ha deslizado desde el servicio a la servidumbre.

Así, vamos a tratar de identificar y valorar la presencia femenina en dos de las instituciones en las que la toma de decisiones tiene realmente impacto en la Iglesia universal: la Curia romana y los sínodos.

\subsubsection{La participación en los órganos de la curia romana}

La Curia romana "es el conjunto de dicasterios y organismos, que ayudan al Romano Pontífice en el ejercicio de su suprema misión pastoral, para el bien y servicio de la Iglesia universal y de las Iglesias particulares, con lo que se refuerzan la unidad de la fe y la comunión del pueblo de Dios y se promueve la misión propia de la Iglesia en el mundo" (Pastor bonus 1).

Así, ejerce sus funciones participando de la potestad ordinaria y propia del Papa en orden a auxiliar a éste.

Por esa razón, tiene un carácter complejo, pero se espera de ella "un funcionamiento eficaz, edificante, disciplinado y ejemplar, no obstante, la diversidad cultural, lingüística y nacional de sus miembros" ${ }^{\text {"28 }}$. Básicamente, los órganos de la curia se clasifican de la siguiente manera: congregaciones, con potestad ejecutiva; tribunales, con potestad judicial; y pontificios consejos y

\footnotetext{
${ }^{26}$ FranCISCO, "Conmemoración del 50 aniversario de la institución del Sínodo de los Obispos", 17 de octubre de 2015, en línea: http://www.vatican.va/content/francesco/es/speeches/2015/october/documents/papafrancesco_20151017_50-anniversario-sinodo.html, consulta 18/05/2020).

${ }^{27}$ C. PeÑa García, "Presencia de la mujer en la situación actual desde la perspectiva jurídicocanónica", CONFER 56 (2017) 401-414.

28 FRANCISCO, "A la Curia romana con ocasión de las felicitaciones navideñas", 22 de diciembre de 2014, en línea: http://w2.vatican.va/content/francesco/es/speeches/2014/december/documents/papafrancesco_20141222_curia-romana.html, (consulta 28/05/2020).
} 
comisiones y otro tipo de oficios que, propiamente, desarrollan una actividad consultiva o asesora pero que, claramente, carecen de potestad de jurisdicción o régimen.

Si atendemos a una información ofrecida por la agencia de comunicaciones de la Santa Sede en marzo de 2020,

En los últimos diez años han crecido tanto el número absoluto como el porcentaje de mujeres en el interior del personal al servicio del Papa y de la Santa Sede [...] En 2010 había 385 mujeres trabajando en la Santa Sede, en 2019 ya eran 649, por lo que su participación en el personal total ha aumentado en la última década de 17,6 a más del $24 \%{ }^{29}$.

Con todo, lo que más interesa a nuestro estudio es, precisamente, la presencia que el Papa llama "incisiva"; ahí también "en total, cinco de las 22 oficinas más importantes de la curia (Secretaría de Estado, secretaría para la Economía, tres dicasterios, nueve congregaciones, cinco consejos, tres tribunales) tienen ahora mujeres en el equipo de liderazgo" 30 .

Ahora bien, siendo importantes estos datos, nos interesa valorar la efectiva "incidencia" de estas mujeres en los lugares en los que han sido incorporadas. Esta cuestión nos obliga a retomar la consideración de eso que Benedicto XVI llamó "problema jurídico" "31, el del ejercicio de la potestad de régimen, o mejor, el de la posibilidad de que quienes no han recibido el sacramento del orden, tengan capacidad para tomar decisiones vinculantes para la vida de los fieles.

El tema, de gran tradición en la historia de la Iglesia, es complejo y disputado. El mismo Papa Francisco pide ayuda a los pastores y teólogos para hacer una interpretación de la cuestión que "podría ayudar a reconocer mejor lo que esto implica con respecto al posible lugar de la mujer allí donde se toman decisiones importantes, en los diversos ámbitos de la Iglesia” (EG 104).

Como hace notar algún autor, a lo largo del segundo milenio llegó a ser doctrina común en la institución, la existencia, por una parte, de una potestad de orden, que se recibe a través del sacramento del orden sagrado y se ejerce en los sacramentos y el culto divino; y, por otro, la de jurisdicción, que se

29 G. SAILER «Mujeres en el Vaticano: la presencia femenina sigue creciendo», en línea: https://www.vaticannews.va/es/vaticano/news/2020-03/mujeres-vaticano-presenciafemenina-sigue-creciendo.html, (consulta 26/05/2020).

30 G. SAILER, "Mujeres en el Vaticano: la presencia femenina sigue creciendo», en línea: https://www.vaticannews.va/es/vaticano/news/2020-03/mujeres-vaticano-presenciafemenina-sigue-creciendo.html, (consulta 26/05/2020)

31 Benedicto XVI, "Entrevista al Santo Padre con motivo de su próximo viaje apostólico a Alemania", 5 de agosto de 2006, en línea: http://www.vatican.va/content/benedictxvi/es/speeches/2006/august/documents/hf_ben-xvi_spe_20060805_intervista.html, (consulta 17/05/2020). 
transmite y recibe a través de la misión canónica, el acto jurídico por el que la autoridad eclesiástica asigna a los súbditos sobre los que puede ejercerse ${ }^{32}$. Esta segunda se pierde, bien cuando cesa el oficio que justificaba la misión, o bien cuando esta misión se revoca. Sin embargo, la publicación del CIC en 1983 volvió a suscitar debate en torno a la posibilidad de que los laicos ejercieran la potestad de régimen porque, si bien el c. 129 \$ 1 y 2 establece que "de la potestad de régimen, que existe en la Iglesia por institución divina, y que se llama también potestad de jurisdicción, son sujetos hábiles, conforme a la norma de las prescripciones del derecho, los sellados por el orden sagrado" y "en el ejercicio de dicha potestad, los fieles laicos pueden cooperar a tenor del derecho", el c. 274 \ 1, señala que "sólo los clérigos pueden obtener oficios para cuyo ejercicio se requiera la potestad de orden o la potestad de régimen eclesiástico".

Este segundo canon ha favorecido la interpretación restrictiva del principio, por ejemplo, en la constitución apostólica Pastor bonus de Juan Pablo II sobre la curia romana. En este texto, admitiéndose la participación de clérigos y laicos como miembros en algunos dicasterios (art. 3.1 y 2), se establece, sin embargo, que son miembros "propiamente dichos" de las congregaciones, los cardenales y obispos (art. 3.3). Es decir que, cualquier incorporación de laicos a las mismas, los convertiría en miembros, pero "no propiamente dichos", "expresión desafortunada porque la condición de un miembro en un colegio (y los dicasterios de la curia tienen una estructura básicamente colegial), nunca puede ser impropia" 33 .

Por otra parte, una situación tan ambigua se complica aún más precisamente por esa condición de colegio que tienen los dicasterios de la curia. La colegialidad marca la igual condición de los miembros que se proyecta de un modo muy notable a la hora de tomar decisiones. Ahora bien, como Pastor bonus también señala que "lo que requiera el ejercicio de la potestad de régimen, se reserva a los que tienen el orden sagrado" (art. 7), de hecho, se limita la participación colegial de los laicos que no tienen potestad de régimen, pues ésta sólo pertenece a los miembros "propiamente dichos".

Así, esta ambigüedad,

lleva a consecuencias no muy congruentes con los principios jurídicos colegiales como, por ejemplo, reservar la votación de algunas cuestiones a los cardenales y obispos miembros del dicasterio, sustrayendo esa competencia a la asamblea plenaria, que es el órgano más importante, por definición, del coetus colegial, al

32 A. VianA, "El problema de la participación de los laicos en la potestad de régimen. Dos vías de solución”, Ius Canonicum 54 (2014) 603-638.

33 A. VianA, "El problema de la participación de los laicos en la potestad de régimen”, 620 (n. 46). 
que se han de reservar el tratamiento y eventual votación de las cuestiones de mayor significado. ${ }^{34}$

Todo este problema jurídico nos hace temer que la presencia de las mujeres en los organismos curiales, principalmente en las congregaciones, que ciertamente tanto ha potenciado el Papa, no pueda tener, hoy por hoy, ese carácter incisivo que Francisco pretende.

Quizás la reforma de la curia que el Papa trata de aplicar y que se fundamentará en la constitución apostólica Praedicate evangelium -que no ha podido ser aprobada todavía-, traiga alguna clave jurídica que defina de un modo definitivo el alcance real de la participación de las mujeres en los órganos con potestad de jurisdicción.

Algunos de los que han tenido acceso a los borradores del documento ${ }^{35}$, señalan que, entre otras cosas, Praedicate evangelium, en general, se aleja de una concepción tradicional de la misma entendida como el brazo de aplicación legal del papado, y re-imagina el papel de la curia en torno a tres principios eclesiológicos centrales: colegialidad, sinodalidad y subsidiariedad.

Así, parece que el texto hace hincapié en la necesidad de que en el futuro el personal de la curia incluya a hombres y mujeres laicos "en roles de importancia y responsabilidad", incluso como jefes de las distintas oficinas.

Uno de los medios que pueden favorecerlo es dejar atrás la distinción entre congregaciones, generalmente vistas como teniendo un tipo de poder ejecutivo, y consejos pontificios, generalmente vistos como asesores. Todas las oficinas principales, excepto la Secretaría de Estado, pasarían a considerarse tras la reforma dicasterios, sin que existiera ninguna diferencia entre ellos. De esta manera, el borrador del texto establecería que un departamento curial "no puede emitir leyes o decretos generales que tengan fuerza de ley, ni puede desviarse de las prescripciones de la ley universal", excepto caso por caso, "aprobado específicamente por el Sumo Pontífice". Además, se señalaría que cualquier "asunto importante, raro y extraordinario" no pueda ser tratado por el Prefecto del dicasterio a menos y hasta que haya resuelto el asunto con el Papa y haya recibido su aprobación.

\footnotetext{
34 A. VIANA, "El problema de la participación de los laicos en la potestad de régimen", 629.

${ }^{35}$ E. Condon, "Analysis: New Vatican Constitution to Centralize Power in State Secretariat", Catholic News Agency, 2 de julio de 2019, en línea: https://www.catholicnewsagency.com/news/analysis-new-vatican-constitution-tocentralize-power-in-state-secretariat-15873, (consulta 19/05/2020); J J. MCELwEE, "Proposed New Apostolic Constitution Reorders Vatican's Offices", National Catholic Reporter, 5 de junio de 2019, https://www.ncronline.org/news/vatican/proposed-newapostolic-constitution-reorders-vaticans-offices, (consulta 19/05/2020).
} 
Si esto es así y si lo dispuesto en el borrador actual de Praedicate evangelium prospera, asistiríamos al final efectivo de la capacidad de cualquier departamento curial de ejercer la autoridad de gobierno papal sobre una base delegada estable.

De esta manera, la aprobación de una reforma de esta naturaleza parece que solventaría el problema jurídico que se desprende del ejercicio de la potestad de orden por quienes no son ministros ordenados, y favorecería una profesionalización del trabajo de la curia que llevaría a considerar como mérito, entre otros, la competencia profesional.

\subsubsection{La participación en el Sínodos de Obispos}

El Sínodo de los Obispos es un órgano colegiado, integrado en la estructura de gobierno de la Iglesia universal, que "durante más de cincuenta años, las asambleas del sínodo se han revelado como un instrumento válido de conocimiento recíproco entre los obispos, oración común, debate leal, profundización de la doctrina cristiana, reforma de las estructuras eclesiásticas y promoción de la actividad pastoral en todo el mundo" 36.

Según establece el CIC (c. 346 \1) "lo integran, cuando se reúne en asamblea general ordinaria, miembros que son, en su mayoría, obispos; unos elegidos para cada asamblea por las conferencias episcopales, según el modo determinado por el derecho peculiar del sínodo; otros designados por el mismo derecho; otros, nombrados directamente por el Romano Pontífice; a ellos se añaden algunos miembros de institutos religiosos clericales elegidos conforme a la norma del mismo derecho peculiar".

La constitución apostólica Episcopalis communio señala que, además de los miembros, pueden participar, en calidad de invitados y sin derecho a voto, expertos (periti), que cooperan en la redacción de los documentos; auditores (auditores), que poseen una competencia particular sobre las cuestiones a tratar; y delegados fraternos (delegati fraterni), pertenecientes a iglesias y comunidades eclesiales que todavía no están en plena comunión con la Iglesia católica. También se pueden añadir algunos invitados especiales (invitati speciales), designados en virtud de su reconocida autoridad ${ }^{37}$.

\footnotetext{
${ }^{36}$ FrANCISCO, Constitución Apostólica Episcopalis communio, 15 de septiembre de 2018, en línea: http://www.vatican.va/content/francesco/es/apost_constitutions/documents/papa-

francesco_costituzione-ap_20180915_episcopalis-communio.html, (consulta 27 de mayo de 2020).

${ }^{37}$ FranCISCO, Constitución Apostólica Episcopalis communio, 15 de septiembre de 2018, en línea: http://www.vatican.va/content/francesco/es/apost_constitutions/documents/papafrancesco_costituzione- ap_20180915_episcopalis-communio.html, (consulta 27 de mayo de 2020) $n^{\circ} 8$.
} 
En la praxis de los últimos sínodos, la presencia de las mujeres en calidad de expertas, auditoras, invitadas etc., se ha ido haciendo más relevante. Así, si en el sínodo de 2018 al menos veintinueve mujeres participaron como auditoras o colaboradoras, y una representó a la Unión internacional de superioras generales (UISG); en el último sínodo (2019) participaron treinta y cinco: dos en calidad de invitadas especiales; cuatro como expertas y veintinueve como auditoras. Además, representando a las UISG, participaron esta vez diez mujeres.

Con todo, su participación en el sínodo también ha despertado un conflicto, en cierta manera, jurídico.

Como hemos visto, Episcopalis communio indica que, además de los miembros (obispos y algunos integrantes de institutos clericales), pueden participar expertos, auditores, delegados, invitados especiales. Ahora bien, los primeros tienen voz y voto, mientras que los segundos no.

Podríamos pensar que es bastante lógico ${ }^{38}$ que sólo los obispos sean miembros de pleno derecho, especialmente si tenemos en cuenta que "durante más de cincuenta años, las asambleas del sínodo se han revelado como un instrumento válido de conocimiento recíproco entre los obispos, oración común, debate leal, profundización de la doctrina cristiana, reforma de las estructuras eclesiásticas, promoción de la actividad pastoral en todo el mundo"39.

Ahora bien, en las nuevas normas el fundamento del sínodo ya no es la colegialidad, sino la sinodalidad, porque:

aunque en su composición se configure como un organismo esencialmente episcopal, el sínodo no vive separado del resto de los fieles. Al contrario, es un instrumento apto para dar voz a todo el Pueblo de Dios precisamente por medio de los obispos, constituidos por Dios «auténticos custodios, intérpretes y testimonios de la fe de toda la Iglesia», mostrándose de asamblea en asamblea como una expresión elocuente de la sinodalidad en cuanto «dimensión constitutiva de la Iglesia» ${ }^{40}$.

38 A. VIANA, "Episcopalis communio. Un comentario a las nuevas normas sobre el sínodo de los obispos”, Revista Española de Derecho Canónico 76 (2019) 361-381.

${ }^{39}$ FrANCISCO, Constitución Apostólica Episcopalis communio, 15 de septiembre de 2018, en línea: http://www.vatican.va/content/francesco/es/apost_constitutions/documents/papa-

francesco_costituzione- ap_20180915_episcopalis-communio.html, (consulta 27 de mayo de 2020) $\mathrm{n}^{\mathrm{o}} 1$.

40 Francisco, Constitución Apostólica Episcopalis communio, 15 de septiembre de 2018, en línea: http://www.vatican.va/content/francesco/es/apost_constitutions/documents/papafrancesco_costituzione- ap_20180915_episcopalis-communio.html, (consulta 27 de mayo de 2020) $\mathrm{n}^{\circ} 6$. 
De esta manera, "se podría plantear en un futuro no lejano una representación más articulada y amplia de fieles no obispos en el sínodo" 41 .

El problema ha surgido después del sínodo de 2018 cuando el Papa Francisco introdujo, al comienzo de la asamblea sinodal, una modificación en su reglamento en virtud de la cual permitió que dos varones no clérigos, superiores generales de los Hnos. de la Doctrina cristiana y Hnos. Maristas, pudieran votar a pesar de no tener la condición clerical propia de los miembros. Es decir, que introdujo una excepción en la norma que llevó a algunos a considerar que, en el próximo sínodo, algunos laicos (hombres y mujeres) podrían participar como miembros de pleno derecho. El asunto afectaba de un modo particular a las representantes de la UISG presentes que se sintieron discriminadas por razón de su sexo.

Y, así, en la rueda de prensa de presentación del siguiente sínodo (2019) el secretario general del mismo tuvo que responder a quienes le preguntaron sobre la participación de las religiosas. En ese momento, M. Baldisseri hizo notar que "el número total de las religiosas - añadió - es superior al de los otros sínodos, lo que testimonia su importancia pastoral y misionera" ${ }^{42}$. Sin embargo, a la pregunta de si las religiosas podrían votar, respondió que se mantendría lo dispuesto en el reglamento de Episcopalis communio, y, por tanto, que las representantes de la UISG no tendrían derecho a ejercer el voto.

Esta decisión fue muy contestada por las religiosas convocadas por Voices of Fait $^{43}$, cuya directora de comunicación, Stephanie Lorenzo, declaró a la prensa que el sínodo comenzaría sin que ninguna mujer tuviera capacidad de votar, aunque las decisiones del mismo afectarían a las religiosas personalmente involucradas en la pastoral de la Amazonia y en las congregaciones femeninas a las que pertenecían. Lorenzo se preguntaba: “¿Qué es lo que está perdiendo nuestra Iglesia sin la experiencia, habilidades, talentos y dones de la mitad de sus miembros?" y advertía: "Queremos llamar la atención sobre este hecho y la falta de mujeres en los roles de toma de decisiones en toda la iglesia" ${ }^{44}$.

41 A. VIANA, "Episcopalis communio". Un comentario a las nuevas normas sobre el sínodo de los obispos”, Revista Española de Derecho Canónico 76 (2019) 366.

42 "Vaticano: presentación del sínodo para la Región Panamazónica - Vatican New", 3 de octubre de 2019, en línea:

https://www.vaticannews.va/es/vaticano/news/2019-10/vaticano-presentacion-delsinodo-para-la-region-panamazonica.html, (consulta 25/05/2020)

43 Se trata de una red de mujeres católicas que crea eventos y promueve, en los medios de comunicación y grupos de redes internacionales, el empoderamiento de las mujeres católicas en la toma de decisiones a nivel local y global de la Iglesia Católica, https:/ / voicesoffaith.org. 44 "El Sinodo de la Amazonía contará con 35 mujeres, el mayor número en una reunión de obispos, aunque sin derecho a voto", Europa Press, 3 de octubre de 2019, en línea: 
Así, aunque ciertamente la participación femenina también ha sido cada vez más notoria en las asambleas sinodales; aunque se ha dado a la sinodalidad una fuerza que no tenía anteriormente; y a pesar de que, siendo un organismo episcopal, "el sínodo no vive separado del resto de los fieles", la presencia incisiva de las mujeres, de la cual el derecho al voto es una manifestación muy creíble, no se ha considerado pertinente hasta el momento.

\section{AlgunAS CONCLUSIONES}

Al terminar de examinar en el magisterio de Francisco, Magisterio en acción, en el que se filtra su pensamiento sobre la presencia femenina y, quizás, esa "teología de la mujer" que, a principios de su pontificado creía necesario acometer, se nos ocurre sintetizar los logros evidentes, así como apuntar algunas incertidumbres y ciertos desafíos.

Como ya dijimos, el punto de partida de la reflexión del Papa está bien identificado; se trata de las mujeres "fuertes y generosas: bautizadoras, catequistas, rezadoras, misioneras, ciertamente llamadas e impulsadas por el Espíritu Santo. Durante siglos las mujeres mantuvieron a la Iglesia en pie en esos lugares con admirable entrega y ardiente fe" (QA 99). Y, entre ellas, con una preferencia indiscutible, las pobres a quienes afectan de manera especial "graves violaciones de los derechos humanos y de nuevas esclavitudes" (QA 14). Podemos afirmar que el Papa Francisco acentúa de manera especial cómo los rostros de la exclusión son, sobre todo, femeninos y, además, indígenas, afroamericanos, inmigrantes, etc. En ese sentido, aun cuando se aprecia una gran continuidad con sus predecesores a la hora de reclamar para hombre y mujer la misma dignidad e iguales derechos, ha visibilizado mucho más las graves injusticias que las mujeres experimentan por el hecho de serlo.

Por otra parte, aunque muchos de sus predecesores han dado paso a una tímida participación efectiva de ellas en la vida pública de la Iglesia, podríamos atrevernos a afirmar que ningún Papa las ha visibilizado tanto, y ninguno lo ha hecho en tantos y tan distintos espacios y foros públicos, muy particularmente en las áreas de gobierno y gestión que - de alguna manera-, dependen del él (el empleo femenino en la Santa Sede ${ }^{45}$; la presencia de mujeres en puestos de

\footnotetext{
https://www.europapress.es/sociedad/noticia-sinodo-amazonia-contara-35-mujeresmayor-numero-reunion-obispos-derecho-voto-20191003150811.html, (consulta 25/05/2020).

45 "Papa Francisco reivindica la figura de la mujer que sabe "cuidar de lo que ya existe", Dariolasamericas.com, 8 de marzo 2020, en línea:

https://www.diariolasamericas.com/mundo/papa-francisco-reivindica-la-figura-la-mujerque-sabe-cuidar-lo-que-ya-existe-n4194446, (consulta 26/05/2020).
} 
responsabilidad de la curia y el Estado Vaticano ${ }^{46}$; la aportación femenina a la investigación y la docencia de la teología $\left.{ }^{47}[\ldots]\right)$.

Por otra parte, el Papa ha pedido ayuda para reflexionar en torno a la cuestión de la naturaleza del poder de jurisdicción en la Iglesia, una cuestión esencial para lograr reformas que no sólo fomenten la presencia incisiva de las mujeres, sino que la consoliden y la haga transversal, de manera que llegue a las iglesias locales y favorezca un cambio de paradigma que normalice su presencia en el diseño eclesial, en el discernimiento de políticas eclesiásticas y de criterios para intentar hacer dialogar a la fe en la historia ${ }^{48}$.

Además, Francisco ha insistido en el principio de sinodalidad, "que se refiere a la corresponsabilidad y a la participación de todo el pueblo de Dios en la vida y la misión de la Iglesia"49, y le ha dado su propia interpretación en el marco de la institución del sínodo, un espacio en el que los protagonistas naturales son los obispos. Esa interpretación ha favorecido ciertamente la cada vez mayor presencia de las mujeres en las tres últimas asambleas.

Con todo, el Papa se muestra muy cauteloso a la hora de pautar esa corresponsabilidad y participación, sobre todo cuando se reduce a la discusión sobre el acceso de la mujer a la ordenación sacerdotal, porque "esta mirada en realidad limitaría las perspectivas, nos orientaría a clericalizar a las mujeres, disminuiría el gran valor de lo que ellas ya han dado y provocaría sutilmente un empobrecimiento de su aporte indispensable" (QA 100).

Precisamente, esta cuestión del clericalismo, que afecta directamente a la relación entre los clérigos y las mujeres en la Iglesia, ha sido uno de los grandes desafíos a los que se ha tenido que enfrentar el Papa. Justamente, a propósito de las mujeres latinoamericanas, pero la afirmación es universalizable, el Papa

${ }^{46}$ Francisco no sólo ha nombrado mujeres para formar parte de las Congregaciones romanas y Academias pontificias; sino que también les ha encomendado dirigir los Museos Vaticanos y el Hospital Bambino Gesú; las ha elegido para actuar como Rectoras de Universidades Pontificias, para integrar la Secretaría permanente del sínodo y el equipo de comunicación del Vaticano y, así, un largo etcétera que no se detiene.

47 G. Mutual, "Premio Ratzinger. El Papa: Teología y arte sigan siendo elevados por el Espíritu”, Vatican News, 17 de noviembre de 2018, en línea:

https://www.vaticannews.va/es/papa/news/2018-11/premio-ratzinger-teologia-artesigan-elevados-poder-espiritu.html, (consulta 26/05/2020).

48 S. ARENAS, "Espero ver a una mujer como cardenal", Vida Nueva - Revista y portal de noticias religiosas y de Iglesia, 26 de agosto de 2019, en línea:

https://www.vidanuevadigital.com/2019/08/26/sandra-arenas-espero-ver-a-una-mujercomo-cardenal/, (consulta 26/05/2020).

49 COMisión TeOlógica InTERnACiOnal, "La sinodalidad en la vida y en la misión de la Iglesia", 2 de marzo de 2018, en línea:

http://www.vatican.va/roman_curia/congregations/cfaith/cti_documents/rc_cti_201803 02_sinodalita_sp.html, (consulta 26/05/2020). 
en su discurso al comité directivo del CELAM, afirmó: "Si queremos una nueva y vivaz etapa de la fe en este continente, no la vamos a obtener sin las mujeres. Por favor, no pueden ser reducidas a siervas de nuestro recalcitrante clericalismo; $[. .$.$] son protagonistas en la Iglesia latinoamericana..."50.$

Por último, el Papa Francisco ha creado un ambiente que ha hecho reaccionar y despertar a las mujeres. Incluso después del abandono de la dirección del suplemento Donne, Chiesa, Mondo de L'Osservatore Romano, Lucetta Scaraffia reconocía el carácter novedoso y excepcional de la experiencia ${ }^{51}$.

Ese ambiente es, probablemente, el que ha favorecido la constitución de grupos como Catholic women speak (https://catholicwomenspeak.com/), una red de grupos de mujeres católicas que, alrededor del mundo, tratan de generar el cambio de su situación en la Iglesia. Este colectivo ha organizado distintos eventos en el marco de los últimos sínodos, y ha publicado los textos teológicos que se han discutido en ellos ${ }^{52}$. Además, Voices of Faith (https://voicesoffaith.org/) es una iniciativa que ha tomado fuerza para crear eventos que visibilicen a las mujeres católicas y promocionen sus reivindicaciones en los medios de comunicación y las redes internacionales; empoderándolas en la toma de decisiones a nivel local y global de la Iglesia Católica.

Por otra parte, el estudio de los textos, los gestos y las palabras, nos suscitan ciertas incertidumbres precisamente en eso que ha venido en llamarse la "teología de la mujer".

En primer lugar, reconociendo que éstas (particularmente en la Iglesia) constituye uno de los temas clave de su agenda, existe un grupo de mujeres que no se reconocen en las reivindicaciones del Papa, o que consideran que no se orientan de tal manera que puedan revertir las situaciones de injusticia y desigualdad que se dan en la Iglesia ${ }^{53}$. Y, así, admitiendo que, para buena parte del mundo, Francisco ha conseguido transmitir la idea de que la Iglesia es la

${ }^{50}$ FrANCISCO, "Viaje apostólico a Colombia: Encuentro con el Comité directivo del CELAM", 7 de septiembre de 2017, en línea:

http://www.vatican.va/content/francesco/es/speeches/2017/september/documents/pap a-francesco_20170907_viaggioapostolico-colombia-celam.html, (consulta 25/05/2020).

${ }^{51}$ L. SCARAFFIA “Querido Papa Francisco: cerramos Donne Chiesa Mondo", Vida Nueva - Revista y portal de noticias religiosas y de Iglesia, 26 de marzo de 2019, en línea:

https://www.vidanuevadigital.com/tribuna/querido-papa-francisco-cerramos-donnechiesa-mondo-lucetta-scaraffia/, (consulta 26/05/2020).

52 T. BeAtTie y otros, (eds.), Visions and vocations (Paulist Press; New York, 2018), CATHOLiC WOMEN SPEAK NETWORK, ed., Catholic women speak: bringing our gifts to the table (Paulist Press; New York 2015).

53 T. REESE, “Pope Francis after a Year”, National Catholic Reporter, 14 de marzo de 2014, en línea: http://www.bishopaccountability.org /news2014/03_04/2014_03_14_

Reese_PopeFrancis.htm, (consulta 27/02/2020). 
institución religiosa que mejor defiende la divinidad de la mujer, no sucede lo mismo con muchas mujeres de occidente. Quizás ha pasado ya el tiempo en el que los varones la consideren como objeto de la teología para evitar así que se siga prodigando una antropología teológica, que también está en este Papa y en sus predecesores, que todavía insiste mucho en la diferente naturaleza de los cuerpos.

Siendo innegable que el cuerpo pone a la mujer en una cercanía primaria a la vida (a diferencia del varón) ${ }^{54}$; si no desarrollamos una antropología de la mutualidad-alteridad, una basada en la imagen de la Trinidad (E. Behr-Siegel ${ }^{55}$ ), un modelo antropológico capaz de mostrar la plenitud de la mujer y el varón en sí mismos, será muy difícil hacer una "teología de la mujer" con tintes de novedad, capaz de iluminar las luchas que traten de revertir las desigualdades que siguen existiendo hoy en la Iglesia y la sociedad ${ }^{56}$.

En este punto conviene anotar que, si bien hay convencimiento de que la ideología de género merece ser discutida, cuestionada y denunciada en sus falacias, sin embargo, el uso del género como categoría de análisis social puede ayudar a aligerar la rigidez del modelo identitario que define los roles de género y puede ayudar a evolucionar en una dirección más flexible para considerar, por ejemplo, las "nuevas masculinidades", y desvelar las posibles trampas de una "teología de la feminidad" 57 .

Además, al reforzar con tanta frecuencia la identificación entre la mujer y la madre (la trampa de la maternidad, S. de Beauvoir dixit), se corre el peligro no sólo de mantener -como ya explicamos- la consideración de la mujer únicamente desde la perspectiva del cuerpo, sino de dejar fuera de su atención a las que no se definen por la maternidad; de reducir enormemente la visión de la biografía de una mujer-madre convirtiendo la maternidad en su único valor a perpetuidad ${ }^{58}$; y de no aportar una nueva reflexión a la teología de la vida consagrada.

En este sentido, las afirmaciones de Francisco sobre padre y madre, maternidad y paternidad en Amoris laetitia, adolecen de esa diferencia y parece

54 M. T. PORCILE, La mujer, espacio de salvación: misión de la mujer en la Iglesia, una perspectiva antropológica (Débora 2; Publicaciones Claretianas, Madrid 1995) 238.

55 É. BeHR-SIEGEL, Le Ministère de la femme dans l'Église (Les Editions du Cerf, París 1987).

56 Algunas conocidas teólogas desconfían de que esto sea posible. I. GEBARA, "El papa Francisco y la teología feminista", Alternativas: revista de análisis y reflexión teológica no. 46 (2013) $131-156$.

${ }^{57}$ J. CHITTISTER, Ser mujer en la Iglesia: memorias espirituales (Servidores y Testigos 103; Sal Terrae, Santander 2006) 164.

58 J. CHITTISTER, ,"Estamos en una encrucijada para las mujeres en la iglesia", Redes Cristianas, accedido 5 de diciembre de 2019, en línea: http://www.redescristianas.net/estamos-en-unaencrucijada-para-las-mujeres-en-la-iglesiajoan-chittister/, (consulta 27/05/2020). 
que hacen más difícil "promover los dones intelectuales, espirituales y pastorales que las mujeres pueden ofrecer a la Iglesia, sin que eso suponga infravalorar nunca cuestiones como la maternidad o la virginidad" ${ }^{59}$. Y no sólo eso. Dichas afirmaciones pueden perpetuar una eclesiología también basada en la diferencia, como la que queda expuesta en la consideración de los llamados principios "petrino" y "mariano". Esta insistencia en la diferencia puede devaluar el esfuerzo de tantas mujeres intelectuales o pastoralistas que se empeñan en difundir un cristianismo inclusivo, igualitario y más comprensible en el marco de las reivindicaciones y conquistas de muchas mujeres. Por otra parte, la recurrente identificación de la Iglesia con lo femenino o con la madre, puede empobrecer la eclesiología si nubla categorías nucleares para el Concilio Vaticano II como "pueblo de Dios" o "sacramento" y, además, no hace sino reforzar roles y arquetipos que necesitan ser examinados porque, quizás, no ayudan a las mujeres a salir de ciertas postraciones culturales ${ }^{60}$.

Por esa razón, nos unimos a las autoras que en este tiempo desconfían del valor que la categoría "genio femenino", se ha prodigado en la elaboración de la "teología de la mujer", ya que, si bien ha tenido una fuerza importante para ir dando visibilidad a las aportaciones del género femenino, hoy resulta ya un lenguaje "rancio y apolillado"; "antídoto de una transformación de la identidad femenina en la dirección de una masculinización cada vez más acentuada" ${ }^{\prime 62}$; o categoría relacionada solo con el cuidado, la caridad eclesial o la catequesis" "33. Y, así, parece que el Papa debería también en esta cuestión "salir a la calle", poner a la Iglesia en salida; "acercarse más a los movimientos de mujeres que reivindican más espacios en la Iglesia y a los movimientos de la sociedad civil en búsqueda de sus derechos. Como él mismo dice "es preciso

${ }^{59}$ P. NAVAS, "La Iglesia en busca de la feminidad", Aletheia, 4 de diciembre de 2013, en línea: https:/ / es.aleteia.org/2013/12/04/la-iglesia-en-busca-de-la-feminidad/, (consulta 27/05/2020).

${ }^{60}$ C. VÉLEZ, "Papa Francisco: No hay feminismo sin protesta", Religión digital, 4 de abril de 2019, en línea: https://www.religiondigital.org/fe_y_vida/Papa-Francisco-feminismoprotesta_7_2109759009.html, (consulta 25 de mayo de 2020).

${ }^{61}$ D. AleIXANDre, "Desde el último banco. Las mujeres en la Iglesia", Vida Nueva - Revista y portal de noticias religiosas y de Iglesia, 21 de octubre de 2016, en línea:

https:/ / www.vidanuevadigital.com/libro/desde-el-ultimo-banco-las-mujeres-en-la-iglesialucetta-sacaraffia-ppc/, (consulta 25/05/2020).

${ }^{62}$ Scaraffia, "La Iglesia y la cuestión de la mujer", A Nosa Voz. Vida e actualidade da Diocese de Vigo, en línea: http://www.anosavoz.com/wp-content/uploads/2016/02/CONFERENCIALUCETTA-SCARAFFIA.pdf, (consulta 26/05/2020).

63 J. LORENZO, "ATE: Nuestra querida Iglesia española es todavía muy masculina y poco abierta a cambios", Vida Nueva - Revista y portal de noticias religiosas y de Iglesia, 11 de noviembre de 2017, en línea: https://www.vidanuevadigital.com/2017/11/11/nuestra-querida-iglesiaespanola-todavia-masculina-poco-abierta-cambios/, (consulta 26/05/2020). 
salir a la calle" para estar con el pueblo y por añadidura también con las mujeres" ${ }^{\prime 4}$.

Por último, reconociendo que la propuesta de reorganización de la curia romana (que parece se apunta en los borradores filtrados) elimina el obstáculo fundamental para una participación incisiva de las mujeres en esas instancias del gobierno de la Iglesia universal, cabe pensar si no se hará en detrimento de la colegialidad, de una participación mayor y de mayor calidad.

Esta cuestión de la participación mayor y de mayor calidad, nos sugiere una serie de desafíos que sentimos como retos y tareas para el futuro.

En primer lugar, el reto de una cada vez mayor profesionalización de la formación de las mujeres que prestan servicio en la Iglesia, puesto que esa parece la forma más legítima de favorecer el acceso en plano de igualdad a las esferas de poder real donde se participa de forma "más incisiva". Este desafío incluye el apoyo explícito a las mujeres que quieran hacer estudios superiores de teología, dedicarse profesionalmente a la misma o contribuir a la formación de los sacerdotes ${ }^{65}$.

En segundo término, el reto de aportar a transformar y simplificar las estructuras eclesiales para que "seamos capaces de vivir una ósmosis que permita la mutua influencia de todos en todos y en todo, vivir en la comunión, vivir la comunión para sabernos enriquecidos comunitariamente con el carisma de algunos ${ }^{966}$.

En esta misma línea, otro desafío que se abre es el de seguir pensando las "nuevas expresiones de ministerialidad eclesial" de las que se habló en el último sínodo $^{67}$, y de las que Francisco habla explícitamente en la exhortación Querida Amaronia (QA 103).

Hay que evitar que las mujeres elegidas para desempeñar tareas de gobierno o participar con voz "incisiva" en los órganos colegiados, estén ahí para "despistar"; es decir, que no sean colocadas en espacios en los que, a la hora de la verdad, o no se toman las decisiones, o no se decide en igualdad de condiciones. Procuremos, además, que no sean elegidas por los hombres que

\footnotetext{
${ }^{64}$ I. GEBARA, "Francisco decepciona a las mujeres", ATRIO (blog), 2 de agosto de 2013, https://www.atrio.org/2013/08/francisco-decepciona-a-las-mujeres/.

65 Francisco, "Visita del Santo Padre Francisco a Nápoles con motivo de un Congreso dedicado al tema «La teología después de la Veritatis Gaudium en el contexto del Mediterráneo»", 21 de junio de 2019, en línea:

http://www.vatican.va/content/francesco/es/speeches/2019/june/documents/papafrancesco_20190621_teologia-napoli.html., (consulta 27/05/2020).

${ }^{66}$ C. InOGÉs, No quiero ser sacerdote. Mujeres al borde de la Iglesia (PPC, Madrid 2020) 117-118.

${ }^{67}$ SínOdo de la Amazonía, Documento final, no 102, en línea: http://www.sinodoamazonico.va/content/sinodoamazonico/es/documentos/documento -final-de-la-asamblea-especial-del-sinodo-de-los-obispo.html, (consulta 28/05/2020).
} 
tienen el poder, porque se corre el riesgo de que, al final, sean nombradas las menos combativas, las más dóciles, y las que no vayan a cuestionar el statu quo.

Como hace notar L. Scaraffia, "las mujeres tienen que participar en la vida de la Iglesia al mismo nivel que lo hacen los hombres, aunque no sean curas. De lo contrario volvemos al clericalismo; también las mujeres aquí serían clericales" ${ }^{\prime \prime}$.

Por último, las mujeres tenemos el desafío de hacernos en la Iglesia cada vez más visibles; con mayor autonomía y con una comprensión ordenada del servicio y el cuidado. $\mathrm{Y}$, cómo no, con aquella determinación que tanto ayudó a Teresa de Jesús que siempre supo de las dificultades que conllevaba ser mujer y serlo en la Iglesia:

Espantábame yo de lo que ponía el demonio contra unas mujercitas y cómo les parecía a todos era gran daño para el lugar solas doce mujeres y la priora, que no han de ser más - digo a los que lo contradecían -, y de vida tan estrecha; que ya que fuera daño o yerro, era para sí mismas; más daño al lugar, no parece llevaba camino; y ellos hallaban tantos, que con buena conciencia lo contradecían ${ }^{69}$.

68 J. OCAMPO, "Entrevista a... Lucetta Scaraffia", 21RS, 20 de abril de 2019, en línea: https://www.21rs.es/es/revista-21/3862_Entrevista-a-Lucetta-Scaraffia.html, (consulta 27/05/2020).

69 Teresa DE Jesús, Libro de la vida, 36, 19, en línea: https://www.santateresadejesus.com/category/escritos/textos-completos, (consulta 27/05/2020). 